\title{
An Unusual Cause of Retained Suprapubic Foley Catheter-Case Report and Literature Review
}

\section{Obi Anselm Okwudili ${ }^{1,2}$, Anikwe Obinna Nnabuife ${ }^{1}$, Ukpa Christopher Ogbu ${ }^{3}$}

${ }^{1}$ Department of surgery, Federal Teaching Hospital Abakaliki Ebonyi State Nigeria.

${ }^{2}$ Department of surgery, Ebonyi State University Abakaliki Ebonyi State Nigeria.

${ }^{3}$ Department of Obstetrics and Gynaecology, Federal Teaching Hospital Abakaliki Ebonyi State Nigeria.

draoobi@yahoo.com;drobianikwe@yahoo.com

ukpachriso@gmail.com

*Corresponding Author: Dr. Obi Anselm Okwudili, Department of surgery, Federal Teaching Hospital Abakaliki Ebonyi State PMB 102 Abakaliki Ebonyi State, Nigeria.

\section{Abstract}

Introduction: Suprapubic Foley catheters may be retained as a result of stone formation over the tip of the catheter. However this is not unusual. What is unusual, is for the stone to be firmly adherent to the bladder mucosa making disimpaction very difficult. This is perhaps the first of such case that will be reported in the literature.

Case Report: The patient, Mr. AB, a 56 year old male butcher of the Igbo tribe of south east Nigeria diagnosed of benign prostatic hyperplasia had been on suprapubic catheter for 20 months unchanged! He presented with suprapubic catheter retention and pericatheter leakage of offensive urine. The patient claimed he was neither informed of the need for periodic change of the catheter nor of the need for definitive management of the underlying condition.

He was managed successfully by suprapubic cystostomy, which revealed not only that a stone had formed over the tip of the catheter but that the stone was firmly adherent to the bladder mucosa.

Conclusion: We advocate proper counseling of patients on indwelling catheters and timely replacement of suprapubic catheters to avoid catheter retention. Clinicians should have a high index of suspicion for stone retention and possibly adherence, especially when suprapubic catheters have been indwelling for several months.

Keywords: Retained suprapubic catheter; vesical stone; stone adherence; suprapubic cystostomy.

\section{INTRODUCTION}

Suprapubic Foley catheters may be retained for a number of reasons, the commonest being non deflation of the catheter balloon[1,2]. Others are pericatheter encrustations[3] and stone formation over the tip or balloon of the catheter[4,5,6]. Other less documented causes are cuffing effect of the deflated balloon[7] or spontaneous true knotting of the catheter on itself[8]. While suprapubic catheter(SPC) retention as a result of stone formation over the tip of the catheter may not be unusual, adherence of the stone to the bladder mucosa is quite unusual. We encountered a patient with retained SPC that was due to adherence of the stone that had formed over the tip of the catheter, to the bladder mucosa. This is an unusual clinical scenario that has not been reported in the literature to the best of our knowledge. We therefore felt compelled to highlight this clinical scenario.

\section{Case Presentation}

A 56-year-old man, was referred to our urology clinic, through the general outpatient department (GOPD) of our hospital on account of peri-catheter leakage of urine which gave him a characteristic ammoniacal odour. History revealed that he had been on SPC which was placed 20 months prior to presentation in a peripheral hospital on account of BOO secondary to 
benign prostatic hyperplasia (BPH). The SPC had not been changed since insertion. The patient claimed he was neither informed of the need for periodic change of the catheter nor of the need for definitive management of the underlying condition. Several attempts had been made at the GOPD to remove the catheter (including cutting off the valve) without success.

Examination revealed an unkempt visibly anxious middle aged man on a retained suprapubic silicone coated Foley catheter. The now discoloured catheter was connected to a urine bag. It was draining cloudy urine into the bag but there was also pericatheter leakage of offensive urine. He was afebrile and in apparent good health, apart from tenderness around the suprapubic cystostomy site. Digital rectal examination revealed moderately enlarged prostate with benign features (firm in consistency and rubbery with intact median sulcus). Systemic examination revealed no comorbidities.

Laboratory investigation consisted of urinalysis, urine microscopy culture and sensitivity (m/c/s), random blood sugar, complete blood count, serum electrolyte urea and creatinine(S/E/U/Cr) estimation and abdomino - pelvic ultrasound scan. The urine culture showed moderate growth of E. coli sensitive to nitrofurantoin. The complete blood count showed relative lymphocytosis. The ultrasound scan revealed a $72 \mathrm{ml}$ prostate that had benign features but with calcific spots on the median lobe. The SPC and its balloon were noted in situ. The patient had a PSA of $2.0 \mathrm{ng} / \mathrm{ml}$. Other investigation results were normal. We made a diagnosis of BPH, Retained SPC and urinary tract infection (UTI).

\section{MANAGEMENT}

Patient was started on tab ciprofloxacin 500mg bid pending results of urine $\mathrm{m} / \mathrm{c} / \mathrm{s}$. He was admitted into the ward and booked for removal of impacted SPC in the theatre the following day. Under spinal anesthesia, the suprapubic cystostomy was enlarged slightly by incising the inferior border. This created an opening wide enough for a finger to be worked around the circumference of the catheter. We confirmed that the catheter was free from the body wall but it was still retained! The incision was then extended further so as to gain free access to the lumen of the bladder to feel the whole length of the catheter. To our astonishment, the catheter tip was encased by a stone (Fig 1), and the stone was firmly adherent to the bladder mucosa. With a series of manipulations with the index finger, the catheter was finally disimpacted and removed en bloc with the stone. The bladder was washed out with normal saline and a new suprapubic silicone coated Foley catheter was placed. The catheter balloon was inflated to $15 \mathrm{mls}$ and the suprapubic cystostomy closed snugly around the new catheter. The intact stone at the tip of the catheter was approximately $6 \mathrm{~cm}$ $x 3 \mathrm{~cm}$ in dimensions. The patient had an uneventful post-operative recovery and was discharged home from the ward on the $5^{\text {th }}$ post-operative day and is being followed up in the clinic. The patient has been regular on his 3 weekly change of catheter and is awaiting definitive surgery.

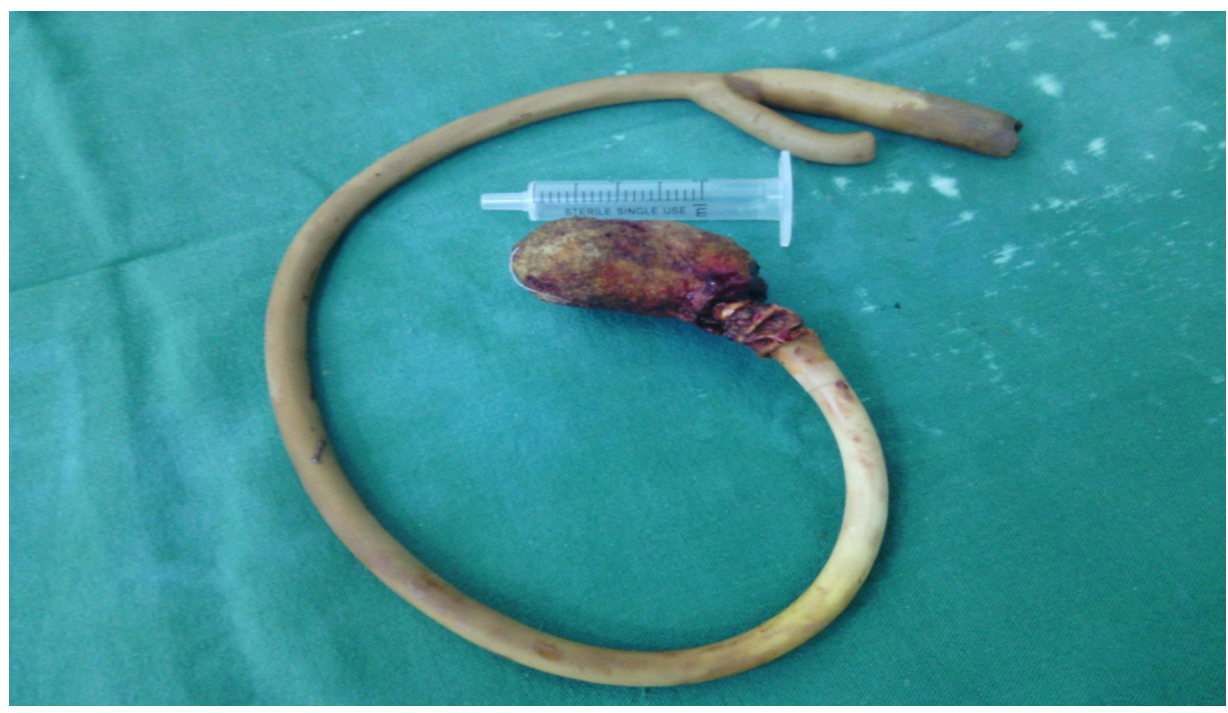

Fig 1. Retained Suprapubic catheter with stone encasing the tip of the catheter 
An Unusual Cause of Retained Suprapubic Foley Catheter-Case Report and Literature Review

\section{DiscuSSION}

Suprapubic catheters may be retained for a number of reasons such as encrustations or stone formation over the intravesical portion of the catheter[4-6,]cuffing effect of the deflated balloon[7] and pericatheter encrustations causing adherence of the catheter to its stoma. Spontaneous true knotting of the catheter on itself causing catheter retention, has also been reported, but is quite rare [8]. Our index case had a stone formed over the tip of the catheter. The stone was missed by the sonologist and to further worsen our dilemma, the stone over the tip of the catheter was firmly adherent to both the catheter and the bladder mucosa (Fig 1).

Stone formation over neglected indwelling catheters is not an unusual clinical scenario [4, 5, 9] . In the first instance the catheter not only presents a ready surface for biofilm formation and crystallization, it also predisposes to UTI and UTI is a predisposing factor for urinary stone formation[9].It is estimated that bacteriuria occurs approximately at an incidence of $10 \%$ per day of catheterization[10]. Our index patient had chronic UTI due to E.Coli. Approximately $1 \%$ of E.Coli are urease positive [11]. Bacterial urease catalyses the conversion of urea to ammonium leading to the alkalinization of urine. The alkaline urine encourages precipitation of calcium, magnesium and phosphate salts leading to stone formation [9]. Stone formation over the catheter tip leads to partial or complete blockage of the catheter. If the blockage is partial as in our index case, urine will drain from both the catheter and the suprapubic cystostomy site.

Various options exist for managing retained suprapubic catheters depending on the aetiology of catheter retention. The aim of treatment is to remove the retained catheter with the simplest procedure, with as little discomfort to the patient as possible and without leaving fragments of the balloon or catheter that could form a nidus for stone formation [12]. We adopt a step-ladder approach starting with the simplest procedure and graduating to more complex treatments.

Our index case is peculiar in that even after deflating the catheter balloon and freeing the catheter from the body wall it was still impacted. Unfortunately the sonologist did not detect the stone around the catheter tip. Sonologists usually require a full bladder for proper visualization of the bladder and intravesical structures. The error in this case may be because the patient could not maintain a full bladder as he was constantly leaking urine through the suprapubic cystostomy. If the stone had been detected our management path could have been different. We could have proceeded directly to suprapubic cystostomy. In addition to opening the bladder we had to use the index finger to disimpact the stone that was firmly adherent to the bladder mucosa. Singh et al [4] and Maison et al [5] have similarly described the use of suprapubic cystostomy to remove retained suprapubic catheters due to stone formation over the catheter tip, but the stones were not adherent to the bladder mucosa like our index case. A minimally invasive option is the use of extra corporeal shock wave lithotripsy (ESWL) to fragment the stone $[13,14]$. ESWL has been shown to be safe in removing vesical stones [13] but we did not have this facility.

\section{ConClusion}

We advocate timely replacement of suprapubic catheters to avoid catheter retention. This will require not only proper patient education by healthcare providers but also measures aimed at reducing the cost of healthcare. A high index of suspicion for stone retention, when indwelling catheters have been neglected for so long is important for accurate diagnosis. A step-ladder approach is reasonable, because oftentimes the exact cause of retention is unknown.

\section{REFERENCES}

[1] Shapiro AJ, Soderdahl DW, Stack RS, et al. Managing the nondeflating urethral catheter. J Am Board Fam Pract 2000; 13:116-19.

[2] Obi AO. Management of non deflating Foley suprapubic catheters-A novel technique. J Coll. of Med. Univ. of Nigeria 2004; 9(1):36-37.

[3] Rath S, Mishra TS, Sasmal PK, Meher S. Pericatheter encrustations: An unusual cause of a retained Foley catheter. BMJ Case Rep. 2016; 14:. doi: 10.1136/bcr-2015-212379.

[4] Singh D, Vasudeva P, Goel A. 'Egg shell' in bladder: A calculus around neglected Foley balloon catheter. Indian J Urol 2010; 26: 299-300.

[5] Maison P, Yenli E. Vesical calculus around neglected foley's catheter: case report. Postgrad. Med. J of Ghana.2013; 2(2):109-111. 
An Unusual Cause of Retained Suprapubic Foley Catheter-Case Report and Literature Review

[6] Ho CCK, Khandasamy Y, Singam P, Goh EH, and Zainuddin ZM. Encrusted and incarcerated urinary bladder catheter: what are the options? Libyan J Med. 2010; 5: 10.3402/ljm.v5i0.5686.

[7] Robinson J. Suprapubic catheterization: Challenges in changing catheters. Br J Community Nurs 2005;10:461-2,464.

[8] Sithasanan N, Kihne M, Naidu RR, Ramanujam TM. Twisted fate of bladder catheters. Med J Malaysia 2006; 61(3):369-70.

[9] Stickler DJ. Clinical complications of urinary catheters caused by crystalline biofilms: something needs to be done. J Intern Med. 2014;276(2):120-9. doi: 10.1111/joim.12220.

[10] Schaeffer AJ. Infections of the urinary tract. In: Wein AJ, Kavoussi LR, Novick AC, et al editors. Campbell-Walsh Urology. vol 1, 9 th ed. Philadelphia: WB Saunders; 2007. p. 223-303.
[11] Nakano M, Iida T, Ohnishi M, Kurokawa K, Takahashi A, Tsukamoto T, Yasunaga T, Hayashi T, Honda T. Association of the Urease Gene with Enterohemorrhagic Escherichia coli Strains Irrespective of Their Serogroups. J. Clin. Microbiol. 2001;39(12):4541-4543.

[12] Hukins DWL, Hickey DS, Kennedy AP. Catheter encrustation by struvite.Br J Urol 1983; 55:304305.

[13] Kojima Y, Yoshimura M, Hayashi Y, et al. Extracorporeal shockwave lithotripsy for vesical lithiasis. Urol Int 1998; 61: 35-8.

[14] Kunzman SA, Srinadh ES, Lala SM, Albusaidi Q. Management of retained encrusted urethral catheter with extracorporeal shockwave lithotripsy. Ind J Urol 2002; 19(1):83-84.

Citation: Obi Anselm Okwudili, Anikwe Obinna Nnabuife, Ukpa Christopher Ogbu. An Unusual Cause of Retained Suprapubic Foley Catheter-Case Report and Literature Review. Archives of Urology. 2018; 1(1): 5-8.

Copyright: (C) 2018 Obi Anselm Okwudili, Anikwe Obinna Nnabuife, Ukpa Christopher Ogbu. This is an open access article distributed under the Creative Commons Attribution License, which permits unrestricted use, distribution, and reproduction in any medium, provided the original work is properly cited. 